\title{
RESPIRABLE DUST EXPOSURE IN UNDERGROUND GOLD MINERS AT OBUASI IN GHANA
}

\author{
F. Y. Bio ${ }^{1}$, S. Sadhra ${ }^{2}$, C. Jackson ${ }^{3}$, P. S. Burge ${ }^{4}$ \\ ${ }^{1}$ University Health Services, Kwame Nkrumah University of Science and Technology, Kumasi-Ghana \\ ${ }^{2}$ Institute of Occupational and Environmental Medicine, The University of Birmingham, $U K$ \\ ${ }^{3}$ School of Health and Policy Studies, University of Central England in Birmingham, UK \\ ${ }^{4}$ Department of Respiratory Medicine, Birmingham Heartlands Hospital, Birmingham, UK
}

\begin{abstract}
Mechanised large-scale mining by European companies which began in the Gold Coast (now Ghana) as early as 1877 presently employs approximately 20,000 people. The Obuasi gold mine is one of the world's oldest and richest goldmines producing about eighty percent of Ghana's gold output. The study was conducted to quantify personal exposure to respirable dust and silica for different underground mining occupations in the Obuasi mine. Personal respirable dust samples were taken from a stratified sample of 125 (10\%) of the 1229 underground miners available for the study. All filter samples were analysed gravimetrically and 1 in 10 filters analysed for their silica content. The mean shift/daily concentration of the underground respirable dust was $0.83 \mathrm{mg} / \mathrm{m}^{3}(\mathrm{SD} \pm 0.55)$ and a range of 0.07 to $2.86 \mathrm{mg} / \mathrm{m}^{3}$ over a mean sampling time of 6 hours. The concentration of respirable silica ranged from 0.01 to $0.12 \mathrm{mg} / \mathrm{m}^{3}$; mean $0.06 \mathrm{mg} / \mathrm{m}^{3}$. The mean silica content of the respirable dust was $9.93 \%$. The present study shows a low personal respirable dust exposure levels as well as silica content in the Obuasi gold mines in Ghana
\end{abstract}

Keywords: Respirable dust; crystalline silica; mining; personal air measurements

\section{INTRODUCTION}

Mining operations including drilling, blasting, and crushing of silica-bearing rocks release respirable particles. The toxicity of the dust generated is dependent on a number of factors including the quantity of crystalline silica inhaled, its particle size distribution and exposure duration. It has also been reported that freshly fractured or broken silica, either by grinding or abrasion is more reactive and of greater toxicity than the old or stale dust (Sluis-Cremer et al. 1987, Wang et al. 1998).

Hnizdo (1992) and Wang \& Banks (1998) state that about 30\% free silica is in respirable gold mine dust, and that the inhalation of the silica particles could be part of the pathogenic processes leading to Chronic Obstructive Pulmonary Disease (COPD). Greaves (2000) also reported that chronic silicosis is associated with moderate exposure $\left(0.05-0.1 \mathrm{mg} / \mathrm{m}^{3}\right)$ to crystalline silica over $20-45 \mathrm{yr}$. The International Agency for Research on Cancer has also stated that there is sufficient evidence in humans for the carcinogenicity of inhaled crystalline silica in the form of quartz or cristobalite from occupational sources (Group 1) (IARC,1997). The current UK maximum exposure limit (MEL) for all forms of respirable crystalline silica is $0.4 \mathrm{mg} / \mathrm{m}^{3}$ (HSE, 2002). Respirable silica levels considered to be representative of underground mining range from 0.05 to $0.84 \mathrm{mg} / \mathrm{m}^{3}$, and have remained unchanged since the 1930s (Hnizdo et al. 1991). Currently large-scale mining in Ghana employs approximately 20000 people.

The town of Obuasi lies in the forest belt of Ghana, approximately $200 \mathrm{~km}$ from the coast at an altitude of 200 metres above sea level. The Obuasi gold mine was opened in March 1890 (Anin, 1987; Ayensu, 1997), and is one of the world's oldest and richest goldmines producing about eighty percent of Ghana's gold output. Expansion and modernisation of the Obuasi mine through the introduction of mechanised mining methods using larger mining equipment started in 1985 (Ayensu, 1997), with the commissioning of the latest shaft in 1998. The mine operates underground providing about 2500 jobs with the underground workings developed along a strike length of $8 \mathrm{~km}$ ( 5 miles) and to a depth of 1.5 kilometres $(5,000$ feet). The gold deposits at the Obuasi mine occur in Birimian graphitic phyllites and sricite-schists transversed by myriads of chutes and lenses of quartz (Anin, 1987; Dumet, 1998). Some of the gold in the quartz vein are contained in sulphides, such as arsenopyrite and pyrite, that require complex techniques for separation, but the majority exists in a free state, which is easily milled (Daily Graphic, 2001). 
The main objectives of this study were to determine respirable dust exposure levels for underground gold miners in Ghana. The has previously not been previously reported. This study was designed to estimate both current and cumulative exposure for different underground mining activities (occupational groups).

\section{MATERIALS AND METHODS}

\section{Study consent from the mine}

The Obuasi mine was chosen for the study since it is the only fully operating underground gold mine and has the largest workforce of the two currently operating mines in Ghana. The management of the Obuasi mine was contacted and visited providing information on: study aims, selection and involvement of study participants, study duration and benefits to both miners and the organisation. Written consent for the study was obtained from the mining company as well as the workers to studied, while ethical clearance for the study was secured from the Ethical Committee of the School of Medical Sciences, Kwame Nkrumah University of Science and Technology, Kumasi, Ghana.

\section{Occupational Groups (OG)}

A team comprising of the researcher, production managers and supervisors classified all underground mining activities into eight different occupational groups. All the Occupational Groups related directly to the production and removal of ore and rock. An Occupational Group represents an occupation covering a group of miners who perform similar tasks, using similar tools and techniques and working under similar conditions. The seven main groups were as follows: drilling, blasting, mucking/loading, tramming, tipping/skipping/rock-breaking, supervisory and engineering; and an eighth (other) occupational group comprising a combination of all general labour duties conducted as required including pipe/track-fitting, welding, shaft tending, pumps attendance and grouting. The underground ventilation system is inspected and maintained by the on-site Mine Ventilation and Rescue Department. The miners in the defined Occupational Groups did not use any formal respiratory protective equipment (RPE), but wet drilling was undertaken.

Table 1: Distribution of the sampled occupations and their mean concentrations

\begin{tabular}{lcr}
\hline Current occupation & Mean conc. $\left(\mathbf{m g} / \mathbf{m}^{\mathbf{3}}\right)$ & \multicolumn{1}{l}{ Range } \\
& & \\
\hline Drilling & $1.09(0.55)$ & $0.27-2.86$ \\
Tipping/R-B & $1.02(0.51)$ & $0.13-2.02$ \\
Supervisory & $0.83(0.50)$ & $0.07-2.13$ \\
Engineering & $0.82(0.66)$ & $0.27-1.27$ \\
Blasting & $0.77(0.63)$ & $0.09-2.12$ \\
Mucking & $0.77(0.33)$ & $0.31-1.75$ \\
Tramming & $0.70(0.63)$ & $0.10-2.85$ \\
Other & $0.64(0.48)$ & $0.07-1.63$ \\
& $\mathbf{0 . 8 3}(\mathbf{0 . 5 5})$ & $\mathbf{0 . 0 7 - 2 . 8 6}$ \\
All & & \\
& & \\
\hline
\end{tabular}


Table 2: Distribution of occupational groups and their mean concentrations

\begin{tabular}{lrrc}
\hline Current occupation & No. in OG (N) & No. sampled (n) & Mean conc. $\left(\mathbf{m g} / \mathbf{m}^{\mathbf{3}}\right)(\mathbf{S D})$ \\
\hline Drilling & 276 & 19 & $1.09(0.55)$ \\
Tipping/R-B & 186 & 27 & $1.02(0.51)$ \\
Supervisory & 144 & 15 & $0.83(0.50)$ \\
Engineering & 175 & 18 & $0.82(0.66)$ \\
Blasting & 84 & 14 & $0.77(0.63)$ \\
Mucking & 148 & 13 & $0.77(0.33)$ \\
Tramming & 63 & 10 & $0.70(0.63)$ \\
Other & 153 & 9 & $0.64(0.48)$ \\
& $\mathbf{1 2 2 9}$ & $\mathbf{1 2 5}$ & $\mathbf{0 . 8 3 ( 0 . 5 5 )}$ \\
All & & & \\
& & & \\
\hline
\end{tabular}

Table 3: Distribution of concentration of respirable dust

\begin{tabular}{|c|c|c|}
\hline Mean Concentration (mg. $\mathrm{m}^{-3}$ ) & $\mathbf{n}$ & $(\%)$ \\
\hline $0.61-0.80$ & 658 & $(53.5)$ \\
\hline $0.81-1.00$ & 211 & $(17.2)$ \\
\hline More than 1.00 & able 2: Distribution of occupationa & ips ând \\
\hline Total & 1229 & $(100.0)$ \\
\hline
\end{tabular}

\section{Personal dust sampling}

Personal respirable dust sampling was undertaken on 125 miners $(10 \%)$ of the 1229 subjects who completed a respiratory symptoms questionnaire between June and November 2001. Every tenth person who completed a respiratory questionnaire was selected for respirable dust sampling and every tenth (12) cassette/filter weighed was selected for silica analysis. Personal sampling was conducted with a portable sampling pump and a sampling head placed on the worker with the inlet positioned in the 'breathing zone' of the worker, about $20-30 \mathrm{~cm}$ from the nose/mouth, on the lapel. A $25 \mathrm{~mm}$ diameter mixed cellulose ester filter (pore size 0.8um) was placed in an SKC (UK) Ltd cyclone sampling head and connected to MSA Escort Pump (Mine Safety Appliances, Pennsylvania, USA), calibrated at $2.2+/-0.1$ 1/min (HSE, 2000). The selected workers wore the pump and the cyclone to their places of work over the daily eight-hour shifts, at a mean temperature of $30^{\circ} \mathrm{C}$ and $93 \%$ relative humidity. At least one personal sample was taken each day of the study for between 6 and 8-hour duration depending on how long the miner stayed underground. Sampling pumps were switched on and flow rates checked just before the miner went underground. The pump flow rates were re-checked before switching off the pumps on their return at the end of the shift.

\section{Analysis of dust samples}

Gravimetric analysis of respirable dust was carried out at the Environmental Laboratory of the Obuasi mine, using a 5-digit 'TARE' BDH Electronic Analytical Balance (precision: $\pm 0.01 \mathrm{mg}$ ). All field filters with controls were weighed at the end of each sampling day. The twelve field silver membrane filters and blank filters (four) were analysed for crystalline silica (quartz) by X-ray Diffraction at Staffordshire University, UK. The filter samples were analysed following the Methods for the Determination of Hazardous Substances (MDHS 51/2) as recommended by the HSE (HSE, 1988). All field and blank filters 
were dried over-night in a Nalgene desiccator (containing silica gel) before weighing both before and after sampling.

\section{Statistical Analysis}

Respirable dust weights were calculated and converted to airborne concentrations. Concentration (mg. $\left.\mathrm{m}^{-3}\right)$ $=$ mass $(\mathrm{w} 2-\mathrm{w} 1)(\mathrm{mg}) /$ volume $\left(\mathrm{m}^{3}\right)$, where $\mathrm{w} 2$ is the weight of filter and dust after sampling and $\mathrm{w} 1$ is the weight of filter alone before sampling. The sample volume is the product of the mean volumetric flow rate in litres per minute and the sampling time in minutes.

Individual total cumulative exposure to dust was estimated as the sum of the current exposure to respirable dust, and the sum of the products of the duration of service at any previous occupations and the estimated mean dust concentrations of the various occupations. Both current and individual total cumulative respirable dust exposures were estimated for 1229 miners. Cumulative exposure was estimated using current mean Occupational Group levels and duration in each Occupational Group since joining the mine. Cumulative exposure was also categorised into three binary indicators of $<10,10-19.99$ and 20-39.99 $\mathrm{mg} / \mathrm{m}^{3} \cdot \mathrm{y}$.

\section{RESULTS}

The mean age of the miners was 39.7 years $(S . D \pm 6 y$ ). The mean total duration of underground work (total exposure) was 12.6 years $(S . D \pm 6.7 \mathrm{y})$, whilst a mean of 9.4 years $(S . D \pm 5.9 \mathrm{y})$ had been spent at the current occupation. The original aim was to sample $20 \%$ of all occupational groups but between $7 \%$ and $17 \%$ was able to be achieved.

The mean shift/daily concentration of the underground respirable dust was $0.83 \mathrm{mg} / \mathrm{m}^{3}(\mathrm{SD} \pm 0.55)$ and a range of 0.07 to $2.86 \mathrm{mg} / \mathrm{m}^{3}$ at a mean sampling time of 6 hours. Tables 1 and 2 show a summary of the distribution of mean respirable dust concentrations and their standard deviations derived from each of the occupational groups. Table 3 shows the grouped miners' exposure to mean airborne respirable dust concentrations.

The total cumulative exposures ranged from 0.64 to $33.02 \mathrm{mg} / \mathrm{m}^{3} . \mathrm{y}$, with a mean of $10.33 \mathrm{mg} / \mathrm{m}^{3} . \mathrm{y}$ ( $\mathrm{SD} \pm$ 5.61) (Table 4). Most of the workers (95\%) had a cumulative exposure of less than $20.00 \mathrm{mg} \cdot \mathrm{m}^{-3} \cdot \mathrm{y}$ (Table $5)$. This of course assumes that the concentrations for the various occupations have not changed over the years. The age and total duration of underground mining were all linearly related to the total cumulative exposure to respirable dust (Figures 1 and 2). The concentration of silica representative of respirable dust in the mine ranged from 0.01 to $0.12 \mathrm{mg} / \mathrm{m}^{3} ;$ mean $0.06 \mathrm{mg} / \mathrm{m}^{3}$. The mean silica content of the respirable dust in the mine was $9.93 \%$, with a range of 0.06 to $19.3 \%$. For current occupations the lowest silica concentration of $0.01 \mathrm{mgm}^{3} . \mathrm{y}$ was observed in engineering and 'other' occupations, whilst the highest concentration of $0.12 \mathrm{mg} / \mathrm{m}^{3} . \mathrm{y}$ was in drilling.

\section{DISCUSSION}

This study found the concentration of personal respirable silica in the Ghanaian gold mine ranged from 0.01 to $0.12 \mathrm{mg} / \mathrm{m}^{3}$; mean $0.06 \mathrm{mg} / \mathrm{m}^{3}$. The mean silica content of the respirable dust in the mine was $9.93 \%$, (range 0.06 to $19.3 \%$ ). The mean level of exposure to respirable dust in the mine was low 0.83 $\mathrm{mg} / \mathrm{m}^{3}$, with very little variation between the exposure levels in the different occupational groups. The miners are only exposed to underground silica, since there is no record of the presence of radon in the Obuasi mine. The other toxic inorganic substances such as arsenic and sulphur which are released during processing are rendered stable. The issue of multiple exposure therefore does not exist.

The virgin rock of the South African gold mine contains about $60 \%$ silica with approximately $30 \%$ free silica in the personal respirable dust 
Table 4: Distribution of occupational groups and mean total cumulative exposure to respirable dust.

\begin{tabular}{lcc}
\hline Current occupation & No. in OG (N) & $\begin{array}{c}\text { Mean total cumulative } \\
\text { exposure }\left(\mathbf{m g} / \mathbf{m}^{3} \cdot \mathbf{y}\right)(\mathbf{S D})\end{array}$ \\
\hline Supervisory & 276 & $14.50(5.40)$ \\
Tipping/Rock-breaking & 186 & $12.58(6.22)$ \\
Blasting & 144 & $12.09(5.04)$ \\
Drilling & 175 & $10.28(6.11)$ \\
Mucking & 84 & $9.86(4.93)$ \\
Tramming & 148 & $9.68(4.70)$ \\
Other & 63 & $8.62(5.00)$ \\
Engineering & 153 & $8.20(5.41)$ \\
& $\mathbf{1 2 2 9}$ & $\mathbf{1 0 . 3 3 ( 5 . 6 1 )}$ \\
& & \\
\hline
\end{tabular}

Table 5: Distribution of total cumulative exposure to respirable dust

\begin{tabular}{lrr}
\hline Cumulative Exposure $\left(\mathbf{m g}^{\left.-\mathbf{m}^{-3} \cdot \mathbf{y}\right)}\right.$ & $\mathrm{n}$ & $\mathbf{( \% )}$ \\
\hline$<10$ & 591 & 48.1 \\
$10-19.99$ & 582 & 47.4 \\
$20-39.99$ & 55 & 4.5 \\
All* & $\mathbf{1 2 2 8}$ & $\mathbf{1 0 0 . 0}$ \\
\hline
\end{tabular}

* Excludes one who did not provide length of service

Figure 1: Distribution of total cumulative exposure to respirable dust among the miners by age

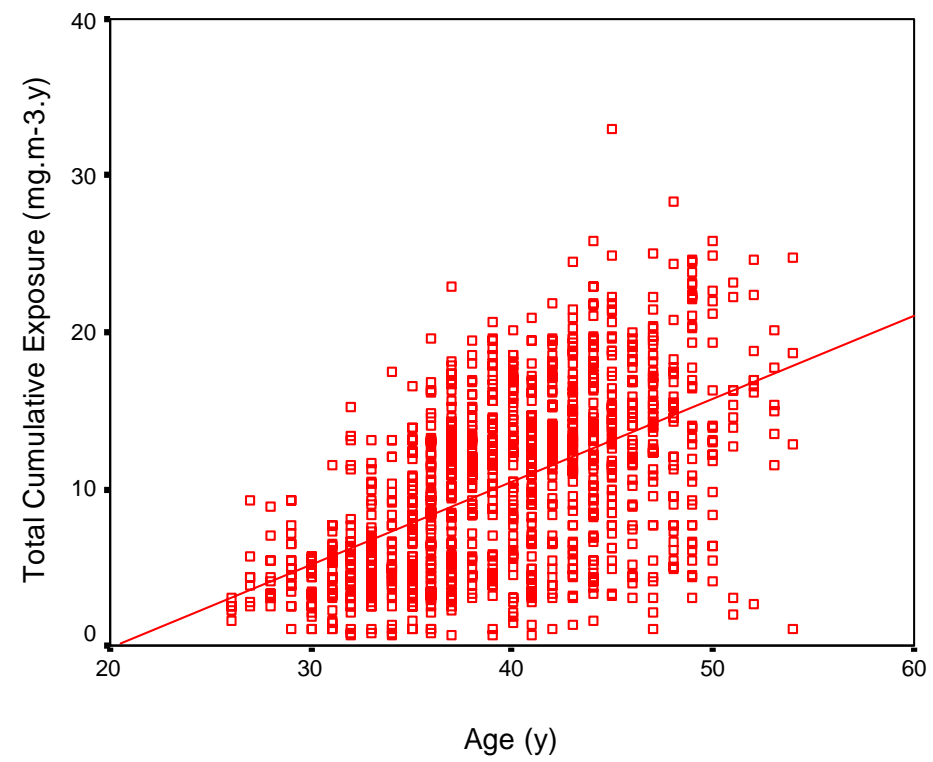


Figure 2: $\quad$ Distribution of total cumulative respirable dust exposure by total duration of underground service

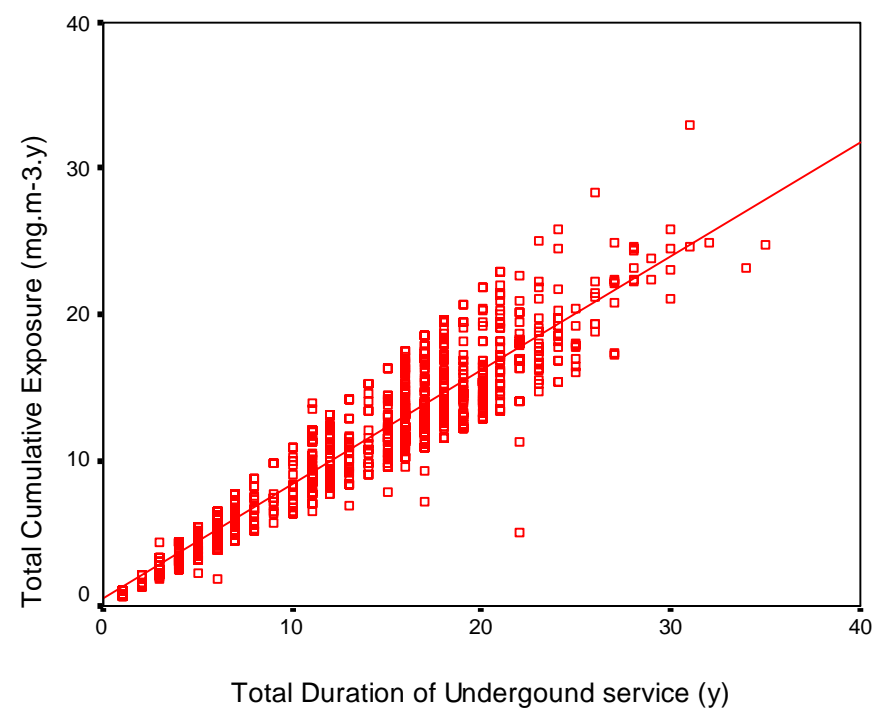

samples and average respirable silica concentration ranging from 0.05 to $0.84 \mathrm{mg} / \mathrm{m}^{3}$ (Hnizdo et al, 1990; Steenland et al, 1995). This data shows that the airborne silica concentration is lower than the Occupational Safety and Health Administration (OHSA), USA standard $\left(0.09 \mathrm{mg} / \mathrm{m}^{3}\right)$, and the United Kingdom Maximal Exposure Limit (MEL) value of $0.4 \mathrm{mg} / \mathrm{m}^{3}$ (8-hour TWA) (HSE, 2002). Other studies in Canada and the United States of America (Muir, 1994; Wang et al, 1998) have found lower percentages of respirable silica of $6 \%$ and $13 \%$ respectively in mines. Muir (1994) suggested that lower percentage of respirable silica dust is less toxic even with comparable cumulative silica exposure levels. The miners at Obuasi were exposed to low levels of silica in the respirable dust hence with less toxicity.

Since working practices might have changed over the years, present dust exposures encountered in the study might be different (higher or lower) from levels experienced some 20 years ago. There is therefore a possibility of bias in calculating cumulative exposure, which assumes that current exposure represents historical exposure for the different occupational groups. No previous or current respirable dust estimates were available for comparison. A limitation in the study was the inability to carry out personal gravimetric respirable dust and X-ray diffraction silica measurements on all the 1236 miners. This was due to the limited financial support for the project.

In conclusion, the present study shows a low personal respirable dust exposure levels as well as silica content in the Obuasi gold mine in Ghana and this had no significant effect on the prevalence of respiratory symptoms on the never smoked miners.

\section{REFERENCES}

Anin, T.E. (1987). Gold in Ghana. Accra: Selwyn Publishers Limited.

Ayensu, E.S. (1997). Ashanti Gold: The African legacy of the world's most precious metal. Marshall Editions Development Ltd, London.

Daily Graphic (2001). Tanzania opens new goldmine. Daily Graphic; July:5.

Dumet, R.E. (1998). El Dorado in West Africa: The gold-mining frontier, African labor, and colonial capitalism in the Gold Coast, 1875-1900. Ohio University Press, Athens, Ohio

Greaves, I.A. (2000). Not-so simple silicosis: a case for public health action. Am J Ind Med; 37:245-51.

Health and Safety Executive (HSE, 1988). Quartz in respirable airborne dusts. Laboratory method using xray diffraction (direct method) MHDS 51/2.

Health and Safety Executive (HSE, 2000). General methods for the sampling and gravimetric analysis of respirable and total inhalable dust. MDHS 14/3. 
Health and Safety Executive (HSE, 2002). EH40/2002: Occupational Exposure Limit 2002. Norwich: HMSO.

Hnizdo, E., Baskind, E., Sluis-Cremer, G.K. (1990). Combined effect of silica dust exposure and tobacco smoking on the prevalence of respiratory impairment among gold miners. Scand $J$ Work Environ Health; 16:411-22

Hnizdo, E. and Sluis-Cremer, G.K. (1991). Silica exposure, silicosis and lung cancer: a mortality study of South African gold miners. Br J Ind Med; 48(1): 53-60.

Hnizdo, E. (1992). Health risks among white South African gold miners-dust, smoking and chronic obstructive pulmonary disease. S Afr Med J; 81(10): 512-7

International Agency for Research on Cancer (IARC, 1997). Silica. IARC Monograph; 68:41

Muir, D.C. (1994). Toxicity of silica dust. [Comment. Letter] Am J Ind Med; 25(5): 769-72.

Sluis-Cremer, G.K., Walters, L.G., Sichel, H.S. (1967). Chronic bronchitis in miners and non-miners: an epidemiological survey of a community in the gold mining area in the Transvaal. Br J Ind Med; 24:112.

Steenland, K., and Brown, D. (1995). Silicosis among gold miners: Exposure-response analyses and risk assessment. Am J Pub Hth; 85(10):1372-1377.

Wang, M. and Banks, D.E. (1998). Airways obstruction and occupational inorganic dust exposure." In Banks DE and Parker JE, (eds.). Occupational lung disease. An international perspective. London: Chapman \& Hall; pp. 69-82.

\section{ACKNOWLEDGEMENT}

The authors wish to acknowledge the immense support of the study subjects (the miners) as well as the management of the Obuasi mine. We are also grateful to the staff of the Institute of Occupational Health, the University of Birmingham and Ms Pam Hayes of the Respiratory Medicine Dept of the Birmingham Heartlands Hospital. The PhD was fully sponsored by the Government of Ghana, and to whom we are very grateful. 